\title{
Cultura, poder y rol de los intelectuales: El dilema de la batalla en el campo
}

\author{
Claudio Esteban Merino Jara
}

Universidad Austral de Chile, Valdivia. Chile. E-mail: cmerinojara@gmail.com

\begin{abstract}
Resumen: El siguiente trabajo se circunscribe en los dilemas que vivencia el profesional, el intelectual que se posiciona en una trinchera del conocimiento que tiene causa común con el enfrentamiento del modelo económico-social actual. Analiza la pugna que existe entre la satisfacción de necesidades de la institución donde trabaja y aquellas necesidades explicitas y latentes del grupo humano donde materializa el ejercicio disciplinario La finalidad, entonces, es sumarse al proyecto social que llama a la militancia en el campo, a la resignificación del compromiso intelectual con la clase oprimida, a la lucha que deben dar en el campo los intelectuales, no solo contra el poder simbólico, sino en contra de la razón neoliberal.
\end{abstract}

Palabras clave: Tecnologías de la subjetivación, campo cultural, biopoder.

\section{Culture, power and the role of intellectuals: The dilemma of the field battle}

\begin{abstract}
The following article confines itself to the dilemmas that the professional experiences, the intellectual who positions himself into a trench of knowledge that has common cause with the clash of the current economic-social model. This work also analyzes the struggle that exists between the satisfaction of the needs of the institution where he works, and those explicit and latent needs of the human group where he materializes his disciplinary exercise. The purpose, then, is to sum oneself to the social project that calls to field militancy, to the resignificance of the intellectual commitment with the oppressed class, to the struggle that intellectuals must give in the field, not only against the symbolic power, but against neoliberal reason.
\end{abstract}

Key words: Subjectivation technologies, cultural field, biopower.

\section{Poder, cultura e papel dos intelectuais: $O$ dilema do campo de batalha}

Resumo: O presente trabalho se limita aos dilemas que a experiência profissional, o intelectual que está posicionado em uma trincheira de conhecimento que tem uma causa comum com o enfrentamento do modelo sócio-econômico atual. Discute a luta entre a satisfação das necessidades da instituição onde ele trabalha e essas necessidades explícitas e latentes do grupo humano que se materializa o exercício disciplinar O objetivo, então, é para participar do projeto social que chama a militância no país, o redefinição do engajamento intelectual com a classe oprimi- 
da, a luta que deve dar estudiosos no campo, não só contra o poder simbólico, mas contra a razão neoliberal.

Palavras-chave: subjetividade, Tecnologia campo cultural, o biopoder

“El saber, que es poder, no conoce límites, ni en la esclavización de las criaturas ni en la condescendencia para con los señores del mundo. Del mismo modo que se halla a disposición de los objetivos de la economía burguesa, en la fábrica y en el campo de batalla, así está también a disposición de los emprendedores, sin distinción de origen”.

(Horkheimer y Adorno 1998)

\section{Introducción}

Desde el cuestionamiento sistemático del paradigma positivista como esquema base para abordar los fenómenos sociales, el discurso ha sido estudiado como variable constitutiva de la sociedad. El llamado giro lingüístico permitió abordar los fenómenos desde la construcción subjetiva del lenguaje.

No obstante, el cambio de las ciencias comprensivas hacia una epistemología militante condicionó nuevos roles en el quehacer profesionalintelectual, tensionando la realidad desde las interacciones sociales y las consecuentes relaciones de poder.

En este escenario el campo social sobre el cual ejerce hegemonía el aparato público institucional, se encuentra constantemente dividido entre las necesidades institucionales fuertemente correlacionadas con la hegemonía del Estado, y aquellas derivadas del proyecto crítico-militante que propicia mayor autonomía y participación de la sociedad.

La estructura del documento comienza con la noción de cultura y su vinculación como medio de subjetivación y reproducción hegemónica dentro de un sistema de razonamiento neoliberal, propende comprender la noción cultural como circuito de circulación normativo y estabilizador. Finalmente el segundo apartado trata de reflexionar acerca de las disyuntivas en las cuales se encuentra el profesional-intelectual al ejercer en una institucionalidad que opera dentro de la lógica del mercado, comprendiéndolo como ente situado dentro de una subcategoría cultural inscrita en el registro del deseo y voluntad de poder.

El texto invita a sumarse al proyecto social que llama a la militancia en el campo, a la resignificación del compromiso intelectual en virtud de la crítica de la razón neoliberal, a la lucha que se debe dar en el campo, no sólo contra el poder simbólico, sino consigo mismo como entes de necesidades. 


\section{El campo cultural como circuito de poder}

"Hay un cuadro de Klee que se titula Angelus Novus. Se ve en él un ángel, al parecer en el momento de alejarse de algo sobre lo cual clava la mirada. Tiene los ojos desorbitados, la boca abierta y las alas tendidas. El ángel de la historia debe tener ese aspecto. Su rostro está vuelto hacia el pasado. En lo que para nosotros aparece como una cadena de acontecimientos, él ve una catástrofe única, que arroja a sus pies ruina sobre ruina, amontonándolas sin cesar. El ángel quisiera detenerse, despertar a los muertos y recomponer lo destruido. Pero un huracán sopla desde el paraíso y se arremolina en sus alas, y es tan fuerte que el ángel ya no puede plegarlas. Este huracán lo arrastra irresistiblemente hacia el futuro, al cual vuelve las espaldas, mientras el cúmulo de ruinas crece ante él hasta el cielo. Este huracán es lo que nosotros llamamos progre-

so”. (Walter Benjamin, 1959)

Ciertamente un ángel que tenga la facultad de observar panorámicamente la historia puede comprender un gran cuadro de una serie de sucesos interconectados, pese a su facultad de comprender los hechos irremediablemente no los puede cambiar, pertenecen a una dimensión que escapa su voluntad, su magia sólo permite admirar ya sea con horror o admiración el devenir desenfrenado del progreso. Pasmado y estupefacto contempla ese gran cuadro, sin poder remediar o minimizar aquellos bosquejos, al mismo tiempo, el huracán lo arrastra irresistiblemente hacia el futuro, atónito ante ese cuadro del pasado, maneja el diagnóstico inevitable de contemplar el presente como un nuevo cuadro restaurado.

La probabilidad que ese cuadro sea admirado por la belleza del horror, impide contemplar el aviso silenciado de aquello que se podría cambiar, ante las características que lo consagran como obra de arte, se inserta el huracán que inevitablemente nos hace olvidar; en la falsa belleza, continuamos bajo el impulso de la autoconservación, disciplinándonos y controlándonos en el gran circuito de los mecanismos de subjetivación cultural.

Los mecanismos de disciplina y control que recorren el campo cultural permiten estabilizar la realidad social, en un juego de aparente movimiento, flexibilidad que no altera los parámetros socialmente establecidos de control; su estrategia es desplegarse en el circuito del campo socio-cultural a través de la concesión y culto de libertades, al mismo tiempo que se fortalecen las tecnologías de seguridad sobre las cuales se realiza la gestión de la población.

Como señala Foucault "los dispositivos de seguridad trabajan, fabrican, organizan, acondicionan un medio aun antes que la noción se haya constituido o asilado. El medio será entonces el ámbito en el cual se da la circulación” (2006:41) 
El carácter fuertemente estético de la cultura facilita el registro de mecanismos de control en las actividades humanas, manifestándose silenciosamente sin que exista un conflicto aparente entre los sujetos sujetados y el aparato institucional que ejerce el poder.

La serie de rasgos que permiten la circulación del poder aproxima la noción de cultura a ámbitos que escapan en lo mediato a su estatus eminentemente estético, constituyéndose en un poderoso agente de diferenciación en el seno de dominio de la elite social, naturalizando la segregación incluso antes de instalarse como noción, y cuando ya el concepto es conciente, éste se encuentra cristalizado e incorporado en la estructura social.

La cristalización silenciosa de la hegemonía de las tecnologías de subjetivación transmiten y mantienen un determinado orden de poder generalmente favorable a la elite social, ya Edward Said (1996) en su obra "Cultura e imperialismo", denunciando desde coordenadas diferentes a las señaladas por Foucault $(1979,1992,1999,2006,2007)$, argumenta cómo el arte, las ciencias y las instituciones transmiten a través de la cultura una determinada ideología, y cuando esa ideología se intenta transgredir, es la propia sociedad la que actúa como ente coercitivo, perpetuándola y sofisticándola en su propia praxis.

La cultura, señala Said, “debe contemplarse tanto por lo que no es y por aquello sobre lo que triunfa cuando resulta consagrada por el Estado, como por lo que positivamente es. Esto significa que la cultura es un sistema de discriminaciones y evaluaciones (...); y también significa que la cultura es un sistema de exclusiones legislado desde arriba, pero promulgado por todo lo largo y ancho del sistema de gobierno, a través del cual se identifican cosas tales como la anarquía, el desorden, la irracionalidad, la inferioridad, el mal gusto y la inmoralidad, para después quedar depositadas fuera de la cultura y permanecer allí mediante el poder del Estado y sus instituciones.” (Said, 2004:24)

Bajo este horizonte, la cultura como medio de circulación anclado en la estructura social y materializado en el ejercicio cotidiano del discurso, disemina las tecnologías de subjetivación desde la estructura de poder, incorporándose al campo social como práctica naturalizada de la sociedad, consolidando, en palabras de José Martí, la obra acumulada de los siglos.

En el caso de la sociedad chilena, la cultura fuertemente impregnada y subjetivada por la memoria del mercado, no solamente restringió las relaciones desde el sentido del consumo; fundamentalmente su estética impregnó la existencia bajo parámetros de éxito, cuya expresión máxima quedó reflejada en el valor de los cuerpos. Posterior al proyecto neoliberal implementado en 1973 (consolidado en su fase concertacionista) se masifico el sentido de los valores socio-económicos de la libertad liberal, consolidando la sujeción de la sociedad.

En tanto sujeto de construcción simbólica de la sociedad, el cuerpo 
y el ser que habita en él (Duch y Mélich 2005; Le Breton 2002) quedó reducido por la cultura neoliberal como objeto de valor de cambio. El ser en el mundo, minimizado por una estructura de sentido, navega en la superficie que impide el encuentro entre existencia y corporeidad. Desencuentro, que deriva en la búsqueda inagotable de la perfección de la existencia, gama ampliada que oscila desde la intervención quirúrgica a detalles sublimes como el cultivo del conocimiento.

Como señala Foucault, "lo que se procura obtener no es una sociedad sometida al efecto mercancía, sino una sociedad sometida a la dinámica competitiva. No una sociedad de supermercado: Una sociedad empresa” (Foucault, 2007:182)

La consolidación del simulacro constante de la sociedad-empresa y la voluntad de poder materializada en la necesidad apremiante de asignarle valor comercial al cuerpo, conlleva un tipo de exclusión que no responde directamente a la acumulación económica, sin embargo, obedece de igual forma a la razón neoliberal, está es la valoración de la existencia según el nivel de productividad e inversión que cada sujeto empresa invierte en su propio cuerpo, así los cuerpos pobres, viejos y enfermos pierden su valor comercial y la sociedad los comienza a excluir e invisibilizar de forma explicita y simbólicamente en la vida cotidiana.

La consumación de la productividad se encuentra tan internalizada en el registro de la sociedad, que adquiere un valor estético que recorre el amplio circuito cultural, desde sus expresiones marginales hasta aquellas grotescamente desarrolladas en los estratos de altos ingresos económicos. En ambos casos, la cultura en su condición poderosa para aceptar, rechazar y legitimar, consolida el circuito de control, potenciando la voluntad de poder y el deseo a niveles cada vez más sofisticados, consumando el culto de la divinidad atea en un simulacro constante en el que se pierde perspectiva de las consecuencias axiológicas de la existencia: cosificación que tiene su nivel más concreto en un tipo de esclavitud sublimada y sus niveles más extremos en la consolidación de una política de la vida, una biopolítica (Agamben 1998; Esposito 2006) que en su extremo se materializa en una tanatopolítica.

Ya Marcuse visionariamente afirmaba: "los esclavos de la sociedad industrial desarrollada son esclavos sublimados, pero son esclavos, porque la esclavitud está determinada no por la obediencia, ni por la rudeza del trabajo, sino por el status de instrumento y la reducción del hombre al estado de cosa. Ésta es la forma más pura de servidumbre: existir como instrumento, como cosa. Y este modo de existencia no se anula si la cosa es animada y elige su alimento material e intelectual, si no siente su «ser cosa», si es una cosa bonita, limpia, móvil” (Marcuse 1993:63)

La valoración ontológica del ser en el mundo, denunciada entre otros por Marcuse, devela el grado de cosificación que ha alcanzado la existencia humana, la fase actual de la razón neoliberal ha propiciado un grado de 
permeabilidad en los registros culturales que hace imposible o con un costo demasiado alto pensar y actuar desde sentidos disímiles al del sujetoempresa. Las prácticas sociales a nivel conciente e inconciente develan en su conjunto la reproducción de los modelos sociales, naturalizados y validados en el trato cotidiano, cuyo grado de control tiene tal nivel de sofisticación que se manifiesta sin alterar ni afectar explícitamente al oprimido, incluso reproduciendo la ideología que lo subyuga bajo el simulacro de la libertad, obstaculizando el desarrollo de la autodeterminación en el culto constante del consumo.

Pues, "lo que está en juego ahora son las necesidades mismas. En la etapa actual, la pregunta ya no es: ¿cómo puede satisfacer el individuo sus propias necesidades sin dañar a los demás?, sino más bien: ¿cómo puede satisfacer sus necesidades sin dañarse a sí mismo, sin reproducir, mediante sus aspiraciones y satisfacciones, su dependencia respecto de un aparato de explotación que, al satisfacer sus necesidades, perpetúa su servidumbre?” (Marcuse, 1969:12)

Una pregunta como ésta, que devela el movimiento subjetivante de la cultura, autosublimación provocada por la voluntad de poder y el culto desmesurado del consumo de satisfacción de necesidades, evidencia la pesadilla que se manifiesta algunas veces inconsciente otras más o menos conciente, respecto de la practica religiosa de la divinidad atea, ritualidad que perpetua las tecnologías de control en una liturgia constante que consolida el nuevo testamento de la hegemonía de subjetivación, es el nuevo orden global, materializado en palabras de Hardt y Negri (2005) como imperio.

“El biopoder llega a ser un agente de producción cuando todo el contexto de reproducción queda incluido bajo el dominio capitalista, es decir, cuando la reproducción y las relaciones vitales que la constituyen se hacen directamente productivas. El biopoder es otro nombre que se le da a la supeditación real de la sociedad bajo el dominio del capital, y ambos son sinónimos del orden productivo globalizado”. (Hardt y Negri 2005:386)

El campo cultural como circuito de poder constituye un medio poderoso para consolidar y sofisticar las tecnologías de subjetivación, agente ideológico no exclusivo del Estado, pero si absolutamente en correspondencia con la razón neoliberal, de esta forma, la hegemonía dominante coopta a los Estados, transformándolos en hábiles medios para cristalizar silenciosamente una política de la vida, que vertiginosamente se traduce en parámetros axiológicos de valor de cambio de la existencia.

El carácter de estabilidad presente en la cultura, constituye el principal obstáculo para generar cambios sociales, sólo siendo posibles modificaciones graduales en la estructura social en la medida que exista el soporte cultural que permita avalar la insubordinación ${ }^{1}$. Aun existiendo precarias probabilidades para establecer un cambio social, necesariamente se debe 
considerar el marco contextual del mundo de la vida en su doble dimensión: en cuanto contexto social y como estructura mental de los sujetos. En consecuencia, un cambio de contexto como proyecto de la modificación de la estructura social, como oposición al ejercicio de la ideología y poder, solo puede surgir desde el cuestionamiento reflexivo del hacer cotidiano, como contramovimiento de la tendencia alienante del deseo.

\section{El dilema de la batalla en el campo}

En este contexto el intelectual-profesional como ente de necesidades vivencia en su ser cuerpo las fisuras político-ideológicas del sistema, observándose en la mayoría de los casos impotente respecto del status quo del peso cultural; la institucionalidad misma, aun cuando tenga una razón de corte ciudadano obstaculiza los procesos en la medida que atentan contra sus intereses institucionales, hecho que generalmente surge cuando el sujeto común y corriente intenta ejercer sus derechos.

"Al subrayar el papel del intelectual como francotirador, he pensado en lo impotente que uno se siente a menudo frente al poderoso entramado de autoridades sociales -medios de comunicación, gobierno y corporaciones, etcétera-, que eliminan cualquier posibilidad real de cambio". (Said, 1996:17)

En efecto, la impotencia del profesional crítico se evidencia en la medida que la realidad se muestra tal como es, en el sentido del peso de la vida factual, imponiéndose bajo parámetros de poder sin importar criterios de veracidad o cuan incongruentemente se asocia a elementos concretos, simplemente es impuesta, socializada y reproducida por la facultad de la sociedad administrada.

“A través de las innumerables agencias de la producción de masas y de su cultura se inculcan al individuo los modos normativos de conducta, presentándolos como los únicos naturales, decentes y razonables. El individuo queda ya determinado sólo como cosa, como elemento estadístico, como éxito o fracaso. Su norma es la autoconservación, la acomodación lograda o no a la objetividad de su función y a los modelos que le son fijados" (Horkheimer y Adorno 1998:82)

Esto implica que la represión hacia el intelectual crítico no sólo ocurre como sanción moral o social, sino a través de formas estilizadas de castigo, la institucionalidad defiende sus intereses con los mecanismos y herramientas que la constitución le asigna, así la estética del ejercicio del poder es efectiva en el control y sanción de aquellos discursos que evidencian y tensionan la realidad.

El intelectual en su rol en el campo, en el ejercicio mismo de la 
profesión, es dependiente de un sistema institucionalizado que al emplearlo consolida sus propias necesidades; el dilema de la batalla en el campo, se manifiesta cuando éstas necesidades (institucionales-personales) son antagónicas a los derechos de las personas, paradojalmente, la misma institucionalidad intenta minimizar las problemáticas sociales con las herramientas económico-sociales que posibilitan y reproducen los males de la sociedad.

El dilema del intelectual, en tanto cómplice o crítico del poder hegemónico, radica entonces en su Dasein. ${ }^{2}$ (Heidegger 2003, 2005), en tanto ser mundano que también vivencia o ejerce la opresión; como sujeto constitutivo del recurso humano del Estado. En este contexto, el dilema de la batalla en el campo, devela la doble vulnerabilidad en la cual se encuentra el intelectual crítico, en primera instancia, como develador de las fisuras que el Estado avala constitucionalmente y finalmente como ser inserto en la mundaneidad.

"El problema particular del intelectual radica en el hecho de que en cada una de las sociedades dominadas por hábitos de expresión existe ya con anterioridad a él mismo una comunidad lingüística, una de cuyas principales funciones es preservar el statu quo, y asegurar que las cosas marchen sin sobresaltos, sin cambios y sin desafíos. (...) El resultado es que la mente está paralizada y permanece inactiva mientras el lenguaje que tiene el efecto de música de fondo en un supermercado resbala sobre la conciencia, seduciéndola a aceptar pasivamente determinadas ideas y sentimientos sin previo examen”. (Said 1996:47).

En síntesis el profesional comprometido con un proyecto social que cuestiona las falencias y fisuras del sistema, en la mayoría de los casos se observa impotente respecto del statu quo del peso cultural; la institucionalidad misma, aun cuando tenga una razón de corte ciudadano, obstaculiza los procesos en la medida que atentan contra sus intereses institucionales.

El dilema de la batalla en el campo surge solo en aquel intelectual de pensamiento crítico (Bourdieu 1999), consciente del peso histórico del condicionamiento cultural e institucional, por el contrario el intelectual funcional, no vivencia dilema alguno, enajenado en la acción tecnológica, carente de crítica, fundamenta su praxis en el hacer, justificando su ética en el compromiso productivo con la institución, consolidándose como un profesional competente y eficiente, hecho en si absolutamente estético y altamente valorado por la ideología de la sociedad industrial avanzada.

Ciertamente la encrucijada del intelectual al asumir una trinchera determinada en el campo, no es algo fácil de resolver, sin embargo, concuerdo con el proyecto de Foucault (1979) cuando plantea las condiciones en las cuales emerge aquello no dicho, las situaciones contextuales en las cuales el discurso silenciado emerge a la luz. ${ }^{2}$ 
Pienso que esto sólo es posible en la medida que la realidad se tensiona a tal punto que se hace insostenible, es decir, cuando el discurso hegemónico pierde el respaldo cultural. En tanto aval superior para autorizar, dominar y legitimar la cultura puede permitir y respaldar el discurso critico cuestionando la oscura noche colonial.

\section{Conclusiones}

Retomando la invitación a la cual convocaba el texto, se puede concluir que la fuerza del campo cultural como circuito de poder constituye un medio difícil de doblegar, en especial por el registro condicionado de la autoconservación.

La razón neoliberal inscrita en los circuitos culturales favorece la reproducción cotidiana del modelo económico y social sobre el cual está erigida nuestra civilización actual, soporte cultural de la hegemonía neoliberalista que se replica cotidianamente en la voluntad de poder de cada individuo.

El carácter normador y estabilizador de la cultura, favorece el medio de contra resistencia a las voces disidentes que promueven un modelo de raíz comunitaria distinta a las libertades y garantías liberales del sujeto empresa, realidad que significa un costo muy alto para establecer contextos alternativos, el culto de la divinidad atea se encuentra poderosamente injerto en nuestra socialización.

El pensar el espacio público como marco en el cual los sujetos establecen el juego de la libre competencia, deriva en la imposibilidad de anhelar lo público desde un estado socio-cultural reciproco comunitario. Desde este prisma, lo socio-cultural se observa fragmentado y disgregado en la búsqueda de la satisfacción personal, perdiendo cohesión, poder y voluntad de cambio.

La subsunción del capitalismo en la vida íntima y afectiva de las personas, cristaliza la hegemonía silenciosa del biopoder, cosificando la existencia y estandarizando al cuerpo como valor de cambio, de esta forma la esclavitud sublimada, a través del consumo y el juego diario de satisfacción de necesidades, imposibilita establecer redes significativas y estables que promuevan cambios de contextos que avalen la insubordinación del nuevo orden imperial.

Bajo este escenario el intelectual-profesional crítico juega constantemente en la disyuntiva de la satisfacción de sus necesidades y aquellas adscritas a la razón social de la institución donde ejerce.

El dilema de la batalla en el campo, en realidad es un juego cruel, en el cual se apuesta con la satisfacción de las propias necesidades, ya sean afectivas o materiales, la responsabilidad de asumir una trinchera militante 
en el campo social, implica la contracorriente estética del circuito cultural subjetivado por las tecnologías de control.

Sin embargo, existen pequeñas grietas que la razón neoliberal aun no ha logrado permear, desde esas grietas que se sustentan en los dilemas del propio campo de la vida, debemos establecer alianzas de cooperación dentro de la comunidad, pensando en las micro resistencias de nuestro acontecer inmediato, aceptando los pequeños espacios de resistencia que no cambian el orden establecido a nivel global, pero al menos otorgan la oportunidad de evitar inmolarse y continuar en la trinchera del conocimiento libertario y emancipador. 


\section{Notas}

${ }^{1}$ Sergio Mansilla plantea al respecto. "Como fuere, la poesía chilena cruzó, no sin pérdidas considerables, el campo minado de la dictadura y el terror institucionalizado. Y lo cruzó protegida por la armadura de la memoria poética de la historia y por el despliegue de subjetividades plurales que entran al ruedo de la escritura a través de sujetos líricos que se proyectan en una dirección que, si no es contraria, al menos tensa al inclusivo yo Wihtmaniano propio de una cierta modernidad poética que viene del siglo XIX: aquélla sintonizada con una forma de modernidad política de corte liberal progresista que destilaba una inagotable confianza en el sí mismo. No es casual, por ejemplo, que la emergencia de la llamada poesía etnocultural, de base indígena o no — que a la fecha ha llegado a convertirse en una especie de movimiento de creación y crítica textual y cultural—es un fenómeno de legitimación de heterogeneidad de escrituras (y de culturas) que despega en la década de los años 80 y 90 del siglo XX, justo en un momento en que se hacía políticamente imprescindible hacer de la pluralidad y diferencia de sujetos, culturalmente situados, pivotes para insubordinar la imaginación contra la violenta homogeneización / para insubordinar autoritaria”. (Mansilla, 2010:83)

${ }^{2}$ Heidegger señala que el Dasein, se entrega a la vida fáctica al dejarse caer en un mundo circunspecto, determinado por un estado de interpretación heredado que envuelve al sujeto a perderse en los modos culturales que permiten la estabilidad del cuidado del ser. La cotidianidad o en sentido Heideggeriano la vida fáctica se mueve en todo momento en un mundo ya interpretado de acuerdo con aquellas perspectivas en las que el mundo comparece y aguarda en calidad objeto de la preocupación. 


\section{Bibliografía}

Agamben, G (1998), Homo Sacer: El poder soberano y la nuda vida, Editorial Pre-textos. Valencia.

Benjamin, W (1959), Tesis sobre la historia y otros fragmentos. En línea http://www.bolivare.unam.mx/traducciones/Sobre $\% 20$ el $\%$ 20concepto\%20de\%20historia.pdf

Bourdieu, P (1999), Intelectuales, política y poder, Eudeba, Buenos Aires.

Ídem (1999), Poder, derecho y clases sociales, Desclée de Brouwer. Bilbao.

Días, E (2010), Las grietas del control, Editorial Biblos. Buenos Aires.

Duch, Ll y Mélich, J, (2005), Escenarios de la corporeidad, Trotta. Madrid .

Esposito, R. (2006), Bíos: biopolítica y filosofía, Amorrortu. Buenos Aires.

Foucault, M (1979), La arqueología del saber, Siglo Veintiuno editores, México.

Ídem (1992), Microfísica del poder, La Piqueta, Madrid.

Ídem (1999), Estrategias de poder, Editorial Paidos, Barcelona.

Ídem (2006), Seguridad, territorio, población, Fondo de Cultura Económica, Buenos Aires.

Ídem (2007), Nacimiento de la biopolítica, Editorial Paidos, Barcelona.

Hardt, M y Negri, A, (2006), Imperio, Editorial Paidos. Buenos Aires.

Heidegger, M (2003), Interpretaciones Fenomenológicas sobre Aristóteles, Trotta. Madrid.

Ídem (2005), Ser y Tiempo, Editorial Universitaria, Santiago de Chile.

Le Breton, D, (2002). Antropología del cuerpo. Nueva Edición. Buenos Aires.

Mansilla, S, (2010), “¿Para qué poesía en tiempos de desigualdad?: Imaginación, memoria y política de la escritura en el contexto de la «cultura de mercado» en el Chile del bicentenario”. En Alpha $N^{\circ}$ 30, Revista de la Universidad de Los Lagos, Osorno. 
Horkheimer, M y Adorno Th (1998), Dialéctica de la ilustración, Editorial Trotta, Valladolid.

Marcuse, H (1993), El hombre unidimensional: Ensayo Sobre la ideología de la sociedad industrial avanzada, Planeta. Buenos Aires.

Ídem (1969), Un ensayo sobre la liberación, Joaquín Mortiz. México.

Said, E. (1996), Representaciones del intelectual, Paidos, Barcelona.

Ídem (1996) Cultura e imperialismo, Anagrama, Barcelona.

Ídem (2004), El mundo, el texto y el crítico, Debate, Buenos Aires.

Recibido: 15.09.2011

Aceptado: 30.09.2012 